University of Nebraska - Lincoln

DigitalCommons@University of Nebraska - Lincoln

Faculty Publications: Department of Teaching, Department of Teaching, Learning and Teacher Learning and Teacher Education

Education

2017

\title{
Perceptions of Linguistically Responsive Teaching in Teacher Candidates/Novice Teachers
}

\author{
Madhavi Tandon \\ University of Colorado Denver, madhavi.tandon@ucdenver.edu \\ Kara Mitchell Viesca \\ University of Nebraska-Lincoln, kara.viesca@unl.edu \\ Colin Hueston \\ University of Colorado Boulder \\ Tamara Milbourn \\ University of Colorado Boulder, Tamara.Milbourn@Colorado.EDU
}

Follow this and additional works at: https://digitalcommons.unl.edu/teachlearnfacpub

Part of the Curriculum and Instruction Commons, and the Teacher Education and Professional

Development Commons

Tandon, Madhavi; Viesca, Kara Mitchell; Hueston, Colin; and Milbourn, Tamara, "Perceptions of Linguistically Responsive Teaching in Teacher Candidates/Novice Teachers" (2017). Faculty Publications: Department of Teaching, Learning and Teacher Education. 335.

https://digitalcommons.unl.edu/teachlearnfacpub/335

This Article is brought to you for free and open access by the Department of Teaching, Learning and Teacher Education at DigitalCommons@University of Nebraska - Lincoln. It has been accepted for inclusion in Faculty Publications: Department of Teaching, Learning and Teacher Education by an authorized administrator of DigitalCommons@University of Nebraska - Lincoln. 


\title{
Perceptions of linguistically responsive teaching in teacher candidates/novice teachers
}

\author{
Madhavi Tandon, Kara Mitchell Viesca, \\ Colin Hueston, and Tamara Milbourn
}

\begin{abstract}
University of Colorado Denver and University of Colorado Boulder
Corresponding author - Madhavi Tandon, PhD madhavi_tandon@yahoo.com; madhavi.tandon@ucdenver.edu University of Colorado Denver, 24863 E. Hoover Pl, Aurora, CO 80016.
\end{abstract}

\begin{abstract}
This qualitative study examined data from 36 teacher candidates and novice teachers to explore their perceptions and understandings of linguistic responsiveness. The findings illustrate the challenge of demonstrating linguistically responsive teaching practices in the early and initial stages of entering the teaching profession, and more research is necessary to understand how to support teachers.
\end{abstract}

Published in Bilingual Research Journal 40:2 (2017), pp 154-168.

doi 10.1080/15235882.2017.1304464

Copyright (C) 2017 the National Association for Bilingual Education; published by Routledge/Taylor \& Francis Group. Used by permission.

Supplemental materials follow the References. 


\section{Introduction}

Generally speaking, the education of multilingual learners (MLLs), students in U.S. public schools who are living their daily lives in two languages or more, is not a successful enterprise (Goldenberg \& Coleman, 2010). Increasingly, content teachers are teaching MLLs at various stages of English proficiency, but they have not received adequate preparation for that work (Lucas, 2011). Therefore, many teacher education programs are striving to improve their efforts in preparing content teachers to work with MLLs (Freeman \& Freeman, 2014). This is a qualitative phenomenological study of the perspectives of teacher candidates (TCs) and novice teachers from an initial licensure program actively engaged in efforts to improve its preparation of general education teachers of MLLs by using the "Linguistically Responsive Teaching” (LRT) conceptual framework (Lucas \& Villegas, 2011). Specifically, we asked: What aspects of the LRT framework do TCs and novice teachers discuss as they reflect on their teacher preparation experiences? What do their reflections illustrate regarding their understanding of LRT over time? Our research suggests that linguistic responsiveness is difficult to attain and that additional work is necessary for initial licensure programs to prepare linguistically responsive teachers.

\section{The teacher education program}

The program in which all of our research participants became teachers is state and nationally accredited, leads to initial licensure in the state, and has an explicit social justice agenda as well as a commitment to preparing urban teachers. It prepares approximately 200 new teachers in elementary, secondary, and special education each year. Through extensive partnerships and a professional development school network, the preparation of teachers in this program is clinically oriented with extensive internships that ensure TCs work with multilingual students as they learn to teach. The schools in which TCs conduct their internships have either diverse populations or very high populations of students of color, multilingual students, and/or students from low-income families and communities. TCs in this program engage in 
coursework that is prescribed and sequential in order to meet initial licensure requirements. Classes are offered through hybrid approaches (combining online and face-to-face resources and meetings) and in collaboration with their extensive clinical work.

In 2011, the U.S. Department of Education Office of English Language Acquisition awarded faculty and administrators for this teacher education program a National Professional Development grant aimed at improving the preparation of general education teachers of MLLs through multiple initiatives. The overarching goal of the grant was to prepare members of this teacher education community (TCs, university faculty, district personnel, site teams, cooperating teachers, and program graduates) to provide linguistically responsive instruction (Lucas \& Villegas, 2011) that supports MLLs' acquisition of language, literacy, and content knowledge. Grant efforts sought to improve curricula and enhance existing networks and relationships by focusing on two levels of initiatives (pre-service and in-service) that were intertwined and sustainable through the development of face-to-face and online learning communities.

A framework that guided the work of the grant and was adopted broadly by the teacher education program was the LRT framework (Lucas \& Villegas, 2011). The LRT framework (Lucas \& Villegas, 2011), described in later sections, offers a conceptual organization of what we know from research regarding the preparation of mainstream teachers of MLLs. The LRT framework was suitable for this work as it is intended for mainstream content teachers, as opposed to the Teachers of English to Speakers of Other Languages (TESOL) standards, which are intended for language specialists. While it is not within the scope of this study to investigate the effectiveness of the teacher education program or the grant efforts related to this framework, it is the purpose of this study to examine the perspectives of TCs and novice teachers enrolled and graduated from this program where grant initiatives focused on improving the preparation of content teachers for MLLs were underway. In other words, we are not evaluating the program nor the grant rather seeking to understand the perspectives that TCs and novice teachers shared when describing their development as TCs and new teachers in relationship to the LRT framework.

To better understand the study, some contextual information regarding how the LRT framework was used to impact the teacher 
preparation program is valuable. Several efforts were undertaken to impact both the TCs in the program as well as the in-service teachers who hosted them in their practicum placements on building the orientations and knowledge/skills associated with the LRT framework. First, face-to-face and online eWorkshops were created and engaged in by teacher educators and in-service teacher mentors. Second, collaborations occurred among teacher education faculty to improve course syllabi and teaching approaches for the TCs. Finally, a new programlevel assessment was developed and implemented that incorporated the LRT framework as a desired learning outcome for TCs across every aspect of their preparation.

\section{Preparing general education teachers to work with MLLs}

Despite being a small and young field (Faltis \& Valdés, 2016; Freeman \& Freeman, 2014; Lucas, 2011), the research on the preparation of general education teachers to work with MLLs does provide important perspectives to consider. Some researchers have illustrated the value of teacher educator faculty development for improving preservice teacher preparation in regards to MLLs (Brisk, 2008; Levine, Howard, \& Moss, 2014; Meskill, 2005; O’Hara \& Pritchard, 2008). Current research also offers insight into teacher preparation policies (López, Scanlan, \& Gundrum, 2013) and instructional practices in teacher preparation courses (Glenn \& Gort, 2014; Jimenez-Silva, Olson, \& Jimenez Hernandez, 2012; Minaya-Rowe, 2004; Schall-Leckrone \& McQuillan, 2014; Schwarzer \& Fuchs, 2014; Sowa, 2009; Wade, Fauske, \& Thompson, 2008; Warren, Reeder, Noftle, Kaiser, \& Jurchan-Rizzo, 2010), such as creating bilingual classrooms in pre-service programs and helping TCs understand language through systemic functional linguistics and exploring their local linguistic landscapes. Research has also focused on TCs' beliefs and dispositions working with MLLs (Katz, 200o; Pappamihiel, 2007; Torok \& Aguilar, 2000; Virtue, 2009), suggesting the importance of TCs viewing MLLs as capable of learning and part of their scope of responsibility.

Research on preparing teachers to work with MLLs has also illustrated the gravity of the challenges teachers and MLLs face. Some teachers have been found to have negative attitudes about teaching 
MLLs (Walker, Shafer, \& Liams, 2004), to be unprepared to support MLL academic development (Li \& Zhang, 2004), and to perpetually overlook MLLs within learning contexts (Reeves, 2009). Further, schools have been illustrated to segregate and marginalize MLLs (Valdés, 1998) as well as foster anxiety among MLLs (Pappamihiel, 2001, 2002). Daniel's (2014) in-depth qualitative study illustrated a general lack of attention to preparing teachers to work with MLLs that still occurs in general teacher preparation programs where MLLs are not often discussed and effective practice and pedagogy is rarely modeled. With such large challenges, ongoing research on the preparation of general education teachers to work with MLLs is important.

Nonetheless, we agree with several researchers' observations that the existing body of research on preparing general education teachers to work with MLLs is in its infancy, with few studies examining teacher outcomes and even fewer providing information on student outcomes (Bunch, 2013; Faltis \& Valdés, 2016). A great deal of the research is self-study of teacher education courses (Jimenez-Silva et al., 2012; Sowa, 2009; Warren et al., 2010) and conceptual in nature (Niño, 2012; Rueda \& Stillman, 2012; Singh \& Suárez-Orozco, 2012). In fact, several conceptual frameworks exist suggesting what teachers should know and be able to do in order to teach MLLs well (Bunch, 2013; De Jong \& Harper, 2005, 2008; Lucas \& Villegas, 2010, 2011; Turkan, De Oliveira, Lee, \& Phelps, 2014). While these studies provide important and valuable insights, we suggest that empirical research such as ours that examines the LRT framework in relationship to $\mathrm{TC} /$ novice teacher development can meaningfully further the research base for preparing teachers to work with MLLs. By engaging in research to further test and explore, from the perspective of TCs/ Novice teachers, the application of one of the conceptual frameworks often utilized and cited in the field, we seek to contribute valuable research perspectives to add to our knowledge regarding the preparation of teachers of MLLs in general teacher preparation programs.

\section{Linguistically responsive teaching framework}

Lucas, Villegas, and Freedson-González (2008) argued that not enough attention was being paid either in teacher preparation or K-12 
classrooms to the linguistic needs of MLLs. Therefore, they called for "linguistically responsive teacher education" and framed education in terms of three types of pedagogical expertise mainstream classroom teachers need: (a) knowledge of the linguistic and academic backgrounds of students, (b) understanding of the language demands of the classroom tasks students are expected to engage in, and (c) the skills necessary to offer the appropriate scaffolding for bilingual learners to successfully participate in classroom tasks. This framework was published in the same year as the first comprehensive literature review of the research on preparing general education teachers to work with MLLs (Lucas \& Grinberg, 2008).

In 2010 and 2011, Lucas and Villegas published expanded versions of their linguistically responsive teacher education framework, based on continued examinations of the research literature. The 2011 framework (Lucas \& Villegas, 2011) provides the most comprehensive perspective of the expertise required of a linguistically responsive teacher and is a framework that has gained notable traction in the literature (Baecher, 2012; Bunch, 2013; Turkan et al., 2014), but it has not yet been extensively empirically examined. Our work in this study is an attempt to dig deeper into this framework through an empirical exploration of how it is expressed by TCs and novice teachers.

Lucas and Villegas (2011) outlined three orientations and four categories of knowledge/skills that content teachers need to do LRT (see Figure 1).

We selected the LRT framework for further investigation and research as it provides a comprehensive perspective of what a linguistically responsive teacher is by combining orientations and knowledge/skills into one framework. Teacher preparation programs need to pay explicit attention to the sociopolitical and racialized contexts that institutions of education in the United States are embedded within while providing TCs with the tools and skills necessary to successfully provide strong language development opportunities in content classrooms. In addition, the LRT framework is consistent with other frameworks in the research literature suggesting what content teachers should know and be able to do in their work with MLLs (Bunch, 2013; De Jong \& Harper, 2005, 2008; Turkan et al., 2014), and it has received substantial attention in the literature as mentioned previously. One of the distinguishing features of this framework is its attention to both 


\section{Orientations of Linguistically Responsive Teachers}

1. Sociolinguistic consciousness: (a) Understanding of the connection between language, culture, and identity; (b) Awareness of the sociopolitical dimensions of language use and language education

2. Value for linguistic diversity

3. Inclination to advocate for ELL students

\section{Knowledge and Skills of Linguistically Responsive Teachers}

1. Learning about ELL students' language backgrounds, experiences, and proficiencies

2. Identifying the language demands of classroom tasks

3. Applying key principles of second language learning: (a) Conversational language proficiency is fundamentally different from academic language proficiency; (b) ELLs need comprehensible input just beyond their current level of proficiency; (c) Social interaction for authentic communicative purposes fosters ELL learning; (d) Skills and concepts learned in the first language transfer to the second language; (e) Anxiety about performing in a second language can interfere with learning.

4. Scaffolding instruction to promote ELL students' learning

Figure 1. Lucas and Villegas's (2011) LRT Framework.

orientations as well as knowledge and skills. Overall, we feel the LRT framework, upon further empirical investigation, could prove useful to advance improved policies and practices regarding the preparation of general education teachers to work with MLLs.

\section{Methodology and data sources}

This qualitative study uses a phenomenological approach to understand the participants' ( $N=36)$ perceptions, perspectives, and understandings of linguistically responsive teaching. The goal of a phenomenological study is to describe the meaning for several individuals of their lived experiences of a common concept or phenomenon (Heidegger, 1982; Husserl, 1963). This approach is particularly useful when the phenomenon of interest has not been well defined or conceptualized and the findings become a vehicle to clarify central issues about the phenomenon (Van Manen, 1990). Although the conceptual framework of linguistically responsive teaching has been defined clearly by Lucas and Villegas (2010, 2011), results from its implementation in teacher education programs have not yet been empirically 
explored. The phenomenon studied herein is not the conceptual framework itself but rather the perceptions and understanding about teaching and learning with MLLs as expressed by TCs and novice teachers in relationship to the LRT framework. The research questions that guided this study were: What aspects of the LRT framework do TCs and novice teachers discuss as they reflect on their teacher preparation experiences? What do their reflections illustrate regarding their understanding of LRT over time?

The research was led by a member of the teacher education faculty and supported by three research associates, all doctoral students at the university. All participants in the study were either enrolled in the teacher education program or had recently graduated from it. The participants were predominantly female, White, and monolingual. All TCs were graduate students, and some had prior work experience in diverse fields such as marketing or advertising. Their ages ranged from early 20 s to 50 s, and some had joined the program to seek a career change. Novice teachers in this study are defined as those teachers who have graduated from the teacher education program and have completed at least one semester of full-time teaching as a paid teacher. The TCs are defined as students enrolled in the program and either in the first, second, third, or fourth semester of the program (see Table 1).

As the objective of phenomenological research is to gather information about the phenomenon without interference from the researcher, our work benefited from the fact that no leading questions about LRT were in the essay prompts or interview/focus group protocols.

Data was collected over two and a half years and consisted of 10 focus groups with TCs $(n=21)$, personal interviews with novice teachers

Table 1. Data sources.

\begin{tabular}{lll} 
Type of Data & Year & Number of Interviews and Participants \\
\hline Alumni interviews & $2012-2013$ & 3 interviews with novice teachers $(\mathrm{n}=3)$ \\
Focus groups & $2012-2014$ & 10 focus group transcripts with TCs $(\mathrm{n}=21)$ \\
Reflective essays (TMs) & $2011-2014$ & 48 reflective essays $(12$ initial essays, each revised three \\
& & times) from TCs $(\mathrm{n}=12)$ \\
Total & Duration $=3$ years & Participants $=36$ \\
& Data sources $=61$ \\
\hline
\end{tabular}


( $n=3)$, and 48 essays written by TCs $(n=12)$. The focus groups were conducted on the university campus with four cohorts of the program. Each cohort's focus group was convened four times, at the end of each semester; two focus groups could not be conducted due to snowstorm- and weather-related closings of the university. Personal interviews were carried out at coffee shops or restaurants with three novice teachers, and each participant was interviewed once for a duration of at least 90 minutes. The reflective essays, known as Teacher Manifestos (TMs), were written by 12 participants at four time points during their year-long program. The teacher education program describes the TMs as a reflective tool that cuts across the entire licensure experience and is a living, breathing, ever-evolving set of "I believe" statements regarding teaching and learning in urban contexts that TCs begin at admission and then revise at particular times throughout the program. The "I believe" statements document a TC's evolving philosophy and are one page in length. The TMs also included a two- to three-page reflection on influences or causes of any evolution and change to the TCs' statements. The first TM was written for admittance, and each subsequent version was updated after each of the three semesters in the program.

\section{Data analysis}

Phenomenological analysis starts by intensive and repetitive readings of the collected data (Lin, 2013). In this study, the first step in analysis was to code (Strauss \& Corbin, 1998) in teams of at least two, but in some cases three, researchers for instances of LRT perceptions across all data sources. All instances across the data that appeared relevant to the phenomenon, teaching and learning with MLLs as understood by the LRT framework, were noted. In a second step, these data identified through the first step were further coded with a set of a priori codes that was derived from the LRT framework as shown in Figure 1 with code names corresponding to aspects of the framework. This approach to coding is helpful in segmenting data and in describing their conceptual properties (Lin, 2013) and was carried out by studying the data line by line to identify instances of LRT elements in the participants' descriptions of their development as new teachers. Whenever the a priori codes failed to capture nuances of LRT perceptions, 
a new descriptive code was created using keywords from the quotation. Therefore, phenomenology as an investigative stance allowed the meaning of LRT to emerge from the participants' perspective, and coding allowed for a typology to be created to represent the variations in these perspectives.

After the initial coding, the selected phrases and themes were grouped according to the a priori codes while ensuring that new and emergent themes were recorded for further analysis. All relevant data were then further analyzed within and across each code as well as longitudinally across the four successive versions of the 12 TC TMs. Based on in-depth analysis of each code, we came to consensus on the findings discussed in the following section.

\section{Findings}

The findings are organized into two subsections in relationship to our two research questions: What aspects of the LRT framework do TC and novice teachers discuss as they reflect on their teacher preparation experiences? What do their reflections illustrate regarding their understanding of LRT over time?

\section{Aspects of LRT framework}

The findings shown in Table $\mathbf{2}$ are organized according to the a priori themes from the LRT framework and discussed in the following section.

Table 2. Code name and its percentage of occurrence (based on number of unique participants).

\begin{tabular}{|c|c|c|c|}
\hline Code Name & $\%$ & Code Name & $\%$ \\
\hline $\begin{array}{l}\text { Orientations of Linguistically } \\
\text { Responsive Teachers }\end{array}$ & & $\begin{array}{l}\text { Knowledge and Skills of Linguistically } \\
\text { Responsive Teachers }\end{array}$ & \\
\hline Sociolinguistic consciousness & $11 \%$ & Knowledge of MLLs' backgrounds & $19 \%$ \\
\hline Value for linguistic diversity & $25 \%$ & Identifying the language demands of classroom tasks & $14 \%$ \\
\hline \multirow[t]{2}{*}{ Inclination to advocate for MLLs } & $22 \%$ & Applying key principles of second language learning & $8 \%$ \\
\hline & & Scaffolding instruction & $33 \%$ \\
\hline
\end{tabular}




\section{Orientations of linguistically responsive teachers}

Orientations of linguistically responsive teachers were interpreted as perspectives, awareness, values, or attitudes that teachers should hold based on Lucas and Villegas's LRT framework to be able to work effectively with MLLs.

\section{Sociolinguistic consciousness}

Four of the 36 participants (11\%) showed an awareness of sociolinguistic consciousness, which is divided into (a) understanding the connection between language, culture, and identity; and (b) awareness of the sociopolitical dimensions of language use and language education (see Figure 1). For content teachers to possess Lucas and Villegas's (2011) first orientation of sociolinguistic consciousness, they must perceive how profoundly language, culture, and identity are intertwined as well as be aware that language use and language education exist within larger sociopolitical contexts. We interpret this orientation to mean that sociolinguistic consciousness should impact how teachers organize their classrooms as they consider MLLs' identities and group memberships within American society. Teachers who are sociolinguistically conscious must also examine their own language values and attitudes, critically assessing their history, development, and potential impact on MLLs in their classrooms.

Several participants referenced aspects of teaching and learning that are encompassed in language, culture, and identity, as discussed in the LRT framework. However, these references could not be interpreted to show that the participants possessed an understanding of sociolinguistic consciousness with regard to "students' ways of expressing themselves and using language [to] reflect cultural values and expectations" (Lucas \& Villegas, 2011, p. 58). For instance, one TC commented on the difference in values between her own upbringing and those of her MLLs, by stating the following, although examples of these different values were not given:

I had major culture shock as the kids were poorer or as poor when I was growing up, but some of these kids didn't really speak English, and some of them had values coming to 
school with them every day that I had never even thought of; it never even crossed my mind and I was in shock.

While perceiving difference is a place to start, these participants did not show that they were "sensitive to the connection between language and identity" (Lucas \& Villegas, 2011, p. 58).

Four participants made direct utterances that revealed their awareness of how the sociopolitical environment affected MLLs. For example, Brittany, a novice teacher spoke of fourth-grade-level content taught to MLLs in high school as follows:

The sheltered class again [...] my guess is shelter is just a buzzword that does not have real intention behind it, because I'm teaching seniors with a 4th-grade textbook and somehow they are supposed to get concepts at the grade level while developing English competency. That feels like something that shelter allows from a political standpoint to say, hey we are teaching them English, but the way I read about shelter, I looked it up; there should be more native language in there or we should give them opportunities to learn in their native language.

Brittany recognized that providing lower-level content to MLLs and not using languages other than English did not meet the needs of the students but were merely moves to satisfy the requirements of compliance. Christine, a TC, addressed inequitable content made available to MLLs by expressing how ironic it was that people want MLLs to contribute more to society, but the content they learn in school does not prepare them to do so. She stated, "We get so many complaints about people who come into our country and aren't productive or aren't you know what is the word, not incorporated, assimilated. You've got to teach that, give them a chance to learn it," referring to content that would help them become productive and assimilated. While we would argue that the end goal of educating MLLs should not be assimilation, Christine was demonstrating an awareness of the sociopolitical/linguistic context in which MLLs were being educated. Amanda, another novice teacher, explicitly recalled a sensitive occurrence: 
I think it [the high school where the internship was done] was about 70\% Latino and 30\% White, and there was a feeling of superiority among the White students, like at Cinco de Mayo they would have extra security guards and the White students would carry American flags that day, and I've never seen that at my school, and it's a pretty similar demographic.

In noting that for this particular holiday the school felt the need for extra security and the White students felt the need to demonstrate their superiority, Amanda demonstrated an understanding of how power and privilege influences students and their schooling.

The quotations suggest that these participants were conscious of some of the sociopolitical dimensions of language, such as the need to provide more equitable content to MLLs and aspects of the sociopolitical context in which students attend school. According to Lucas and Villegas (2011), teachers who are aware of the sociopolitical dimension of language "understand their students' experiences as speakers of subordinated languages and recognize that the challenges they face are partly political, extending beyond the cognitive difficulties of learning a second language" (p. 59). We saw evidence that one novice teacher and three TCs were at least beginning to understand how sociopolitical contexts can impact MLLs' school and learning experiences.

\section{Value for linguistic diversity}

Teachers who have this orientation prize learning about other languages, acknowledge and praise their MLLs' multilingualism, and incorporate opportunities for MLLs to use and leverage their home languages to achieve academic success. Data revealed that nine of the 36 participants (25\%) valued linguistic diversity by praising or appreciating students' abilities for straddling two or more cultures and languages. As expressed by Leah, a TC: "You've got English, now let's validate that you know another language.” Alison, another TC, expressed the desire that people in the United States should "value the multicultural experience" to the point that all people might endeavor to learn multiple languages. The general trend revealed was that while participants lauded linguistically diverse environments, for example by 
expressing joy over the fact that "an assistant principal who speaks Spanish" was hired, there was little evidence to indicate that the participants actually performed actions that promoted a value for linguistic diversity in the classroom or in their schools. One participant did describe how the clinical teacher she interned with actively told students to maintain their native language while also stressing the need to be bilingual. Nevertheless, there were little data that alluded to the participants having performed these acts themselves or that they had attempted to "foster positive attitudes toward ELLs" (Lucas \& Villegas, 2011, p. 59) by increasing diversity in school faculty or other methods. Data indicated that only nine participants had started to understand the importance of showing "respect for and interest in students' home languages (p. 6o).

\section{Inclination to advocate for $M L L S$}

To have this orientation, we feel teachers must recognize the importance of talking to colleagues, administrators, and elected officials about classroom practices and education policies that support MLLs' language development. In addition, they need to be willing to dispute practices and policies that have the potential to harm MLLs. Of the entire sample, eight participants (22\%) demonstrated an inclination to advocate for MLLs. The manner in which the teachers advocated varied, with some participants appearing to have more of an active role in advocating and others being more introspective. For example, one participant addressed the need to give voice to the students and ensure that they would be able to succeed, while another participant explained how they would stay up at night thinking about how to teach the MLLs in such a manner that would equip the students with the necessary skills to succeed. Another participant, Victoria, challenged the belief held by colleagues that MLLs would not be able to handle academic work at their current grade level if it were to be given, stating “They are saying across the board that we can't do this curriculum with our ELLs, and that's not true." She had begun to challenge the deficit perspective prevalent at the school in small ways by offering the same content and same language scaffolds to all the students in the classroom and eventually taking them away when no longer needed. One of the TCs in a focus group engaged in similar activism by finding 
grade- and age-appropriate texts for their MLLs in high school: "I did some lessons with them; I went on to Wikipedia and pulled some native language texts for them to work on."

This example, as well as the one prior, illustrate advocacy by means of adapting the materials and teaching methods of the classroom ( $\mathrm{Lu}-$ cas \& Villegas, 2011). These forms of activism on behalf of MLLs, by working within existing schoolwide policies and/or thinking, was an indication of embracing multilingualism and implementing it in practice. Overall data revealed that most participants expressed empathy and a desire to improve the educational experiences of the MLLs; however, examples of the explicit actions and advocacy that they performed for the students were less frequent.

\section{Knowledge and skills of linguistically responsive teachers}

Lucas and Villegas (2011) framework for LRT indicates that the knowledge and skills required from linguistically responsive teachers focus more on active participation by teachers in addressing and bringing equity to the education of MLLs in the classroom. Linguistically responsive teachers would not only recognize the importance and value of living in two or more languages but would take steps to increase their own competency in learning about the needs of MLLs and finding resources, tools, and strategies to meet these needs. Some of the active measures proposed by Lucas and Villegas (2011) include making home visits, learning to make connections between content and students' lives, increasing personal interactions with MLLs inside and outside the classrooms, and having the ability to use all available information to modify teaching and learning with MLLs.

\section{Learning about MLLs' language backgrounds, experiences, and proficiencies}

Seven participants (19\%) in the study demonstrated an eagerness to learn about their MLLs' backgrounds "to help students make connections between their prior knowledge and experience and new ideas to be learned" (Lucas \& Villegas, 2011, p. 61). The participants discussed different strategies that would help them understand the lives and experiences of MLLs outside the classroom, such as using opportunities 
with writing assignments, creating spaces for open discussions, forming personal connections, taking the time to know them, and learning their moods. One novice teacher stated that she was engaged in “joint learning" with her students and looked forward to enriching her Spanish with input from her students from Mexico and Central America. Analyses indicated that some of participants were compiling a repertoire of potential strategies for learning about their students' lives, and some others were actively implementing them in their internships and classrooms, as shared by one participant: "I made a huge effort to get to know my kiddos ... what they do on weekends, about their parents, getting to know them as persons." However, it was evident that actively engaging with students required effort that some regarded as difficult and emotional. Some of the participants described the process of getting to know the MLLs in their classrooms as "overwhelming," “challenging," and "stressful.” Furthermore, although participants were aware that MLLs language backgrounds and life experiences needed to be valued and respected and there existed a connection between their backgrounds and learning, there was minimal knowledge displayed about incorporating this information into lesson plans and content being taught in the classroom that would be beneficial to MLLs.

\section{Identifying language demands of classroom tasks}

The skills required from linguistically responsive teachers to identify the language demands of classroom tasks include the ability to analyze the linguistic demands of oral and written discourse, to identify key vocabulary, to understand semantic and syntactic complexity of language used in written materials, and to know specific ways students are expected to use language to complete learning tasks. To successfully identify the language demands of a class and specific tasks, teachers must examine at the very least the linguistic features of written texts and its Academic English demands, which can only be achieved by learning fundamental linguistics (Lucas \& Villegas, 2011).

Four TCs and one novice teacher (14\%) indicated that they had started to understand the intricacies of varying language demands within a single classroom. During the focus groups, TCs used phrases such as "five levels of English," which referred to the standards used 
by the state for English, and "differentiated assessments," which indicated how they were making sense of the various levels of English that existed in schools and an awareness that assignments and assessments needed to be modified based on the students' level of English. Brittany, the novice teacher, based on her year-long experience of working in a linguistically diverse classroom, was able to pinpoint some of the issues that she was noticing about improper placement of MLLs in language ability groups and the challenges of having to work with "mismatched" groups. She said:

The placements have been kind of strange so I have some students who have been placed with my English 2 who really should be in English 3 or in mainstream English with supports, and I have students in my English 3 who might have been better served in English 2.

Beyond developing an initial awareness about linguistic demands of a classroom, we can state that our participants' awareness remained at a superficial level, as the discussion never included reference to the linguistic and syntactic analysis of English that would have helped the participants to analyze, break down, and modify texts for MLLs.

\section{Applying key principles of second language learning}

"Linguistically responsive teachers understand the process of learning a second language and can apply this understanding in teaching ELLs" (Lucas \& Villegas, 2011, p. 62); however, only three participants (8\%) demonstrated an initial awareness of this process. For example, one TC stated that students were "grouped according to ability" in their classroom to ensure that MLLs had strong native speakers of English in their groups; this participant also went on to add that this was "a lot of extra work but was not enough." Another TC discussed the importance of teaching her students about code-switching between academic and conversational English, and a novice teacher briefly made a reference to the idea of comprehensible input.

However, some participants expressed a lack of knowledge/skills about the process of learning a second language and applying it. Megan, another novice teacher, stated that as she reflected about her 
work with MLLs, she had realized that "I'm not doing a very good job with it" by trying to combine state standards for English and for MLLs at the same time. Megan had realized that including too many activities and strategies in the lessons had in fact been detrimental to MLLs and after reflection realized that she would introduce fewer activities and repeat them for a few weeks to set a pattern. Amanda, a novice teacher, stated that she needed more time to "figure out strategies that would help meet the needs of ELL and on-track students." In the case of these two novice teachers, Megan and Amanda, their experience and daily work of teaching and learning with MLLs had set them on a path of trial and error regarding best practices for MLLs. In sum, one of the novice teacher and only two of the TCs made a direct reference to any of the key principles of second language acquisition as listed by Lucas and Villegas (2011) (see Figure 1). In addition, as compared to TCs, novice teachers had somewhat more insight into how MLLs in their classrooms were learning and how they could modify their strategies to enhance learning, but they depended on trying out different alternatives instead of using strategies and activities supported by strong empirical evidence from the field of second language acquisition research.

\section{Scaffolding instruction to promote learning for MLLS}

Twelve participants (33\%) mentioned different types of instructional scaffolding that they planned to use or were using with their MLLs at the time of data collection. Lucas and Villegas (2011) describe scaffolding as "the instructional response to Vygotsky's (1978) theory of zone of proximal development" and "in the form of temporary support, helps a learner carry out learning tasks beyond her/his current capability" (p. 65). The scaffolding strategies most mentioned by participants involved supporting their oral/aural development and were either relevant to the modification of oral language by the teacher or indicated the use of supports such as native language grouping, explaining difficult words and ideas, preteaching vocabulary, and creating opportunities in the classroom for discussions. The second group of strategies that the participants referred to were extralinguistic supports in the form of visual cues, graphic organizers, and alternative assignments followed by modification of written texts and clear and explicit instructions. However, although many participants expressed 
the need to scaffold instruction, they did so without mentioning or discussing principles of second language acquisition. Thus data indicated that although the participants did not overtly make connections between theories of second language acquisition and learning, they had taken on the initiative of scaffolding instruction to support MLLs in ways that they had either seen been done before or had tried and been successful.

\section{Changes in understanding LRT over time}

After looking for connections to the LRT framework across all of the data sources, data were examined longitudinally. This investigation was possible because within our data set, there were four iterations of Teacher Manifestos (TM) from 12 TC participants (see Table 1). To search for the development of LRT orientations and knowledge and skills across the TCs' drafts, we first examined the four drafts of each of the 12 participants' TMs to identify the draft in which each TC first explicitly addressed language in their teaching philosophy. Then we compared the context of the first appearance of a languagerelated topic with any subsequent appearances in later drafts to determine whether the TCs continued to revisit their ideas about language and education as they moved through the program. Three TCs mentioned language in the initial drafts of their TMs, which were also their program admission essays. All three of these TCs continued to revisit their ideas on language and education in subsequent drafts. Three TCs introduced the topic of language for the first time in their second TM draft. One of these TCs revisited the topic of language in a later draft, whereas the other two TCs did not make any revisions. Two TCs raised language as an issue in their third TM draft, with only one of the TCs subsequently revisiting the topic of language in the final draft. Four TCs never mentioned language in any draft of their TMs (see Table 3 ).

Table 3. Longitudinal analysis of teacher manifestos.

\begin{tabular}{lrrrrrr} 
& \multicolumn{5}{c}{ No. of Participants in } \\
& Never & TM\#1 & TM\#2 & TM\#3 & TM\#4 & Total \\
\hline First Reference & $\mathrm{n} / \mathrm{a}$ & 3 & 3 & 2 & 0 & 8 \\
Revisions & $\mathrm{n} / \mathrm{a}$ & $\mathrm{n} / \mathrm{a}$ & 3 & 2 & 4 & 9 \\
\hline
\end{tabular}


Our next step was to delve more deeply into the content of the TMs. First, we looked closely at the drafts of the TCs who never mentioned language. In this group of TMs, TCs did address differences in cultures and how it impacted their view of good education practice. For example, one participant planned to "celebrate all cultures represented in the classroom as well as those that my students learn about," and another participant stated that "all students are capable learners no matter their background." However, these statements fall significantly short of demonstrating linguistic responsiveness as conceptualized in the LRT framework of Lucas and Villegas (2011). These four TCs did not specifically address language as an important component of their teaching philosophy, and their understanding of multiculturalism in general was often expressed at a surface level.

Even TCs who mentioned language in their first TM draft and then revisited their ideas in later drafts did not necessarily express a deep level of linguistic responsiveness, though they did demonstrate some growth. For example, Josh, a TC, began with a "barrier" metaphor for language in the first TM:

In urban schools, teachers are confronted with a multiple of different cultures, leading to having barriers- language being one among the many. I have the desire to make sure to my fullest ability a classroom that acknowledges the cultural and linguistic differences.

Though Josh's ideas about language had evolved somewhat by the final draft, he still referred to language as a barrier:

Teachers daily are presented with the challenge of language barriers; leading to miscommunication. ... I have the desire to learn from and welcome my students' culture and linguistic differences and will provide the appropriate accommodations to all my students' needs pertaining to their academic growth, ELL learners, IEP plans, and the gifted.

Josh had moved from wanting to create a classroom that "acknowledges" cultural and linguistic differences to a classroom in which the TC could "learn from" (as opposed to "learn about") students' 
differences and welcome them in the classroom, an indication of valuing linguistic diversity. However, the final draft of his TM did not suggest that he had acquired the other LRT orientations and knowledge and skills that Lucas and Villegas (2011) outline.

Similarly, Susan also mentioned language as a barrier in the first TM: “Too often have we heard stories where a disadvantaged student (e.g., an English Language Learner) is placed in low-track classes simply because there is a language barrier." However, Susan offered this viewpoint to criticize the practice. In addition, she addressed language again later in the same TM, this time accompanied by a suggestion of sociolinguistic consciousness:

As a teacher, I believe my primary job is to equip students with the necessary tools for life beyond the classroom. Middle and upper classes define the social constructions of our postmodern society, revoking access to institutions to nonmainstream groups. Teaching the language of the dominant culture allows students to function within a mainstreamed society. I will provide students with the proper social skills to function within the dominant culture while validating and embracing each child's unique cultural background.

Furthermore, by the third draft, Susan had developed a teaching philosophy that demonstrated the highest level of LRT of all the participants' TMs, including two direct references to being linguistically responsive:

As a teacher, I will know each of my students individually and take the time to know their cultural and linguistic backgrounds and experiences. ... Every classroom contains students from a wide spectrum of cultural and linguistic backgrounds who bring essential assets to the student body. Tapping into each student's funds of knowledge gives students the opportunity to express themselves in a manner that is most meaningful for them that ultimately leads to engagement and true learning. This was especially important at my site school, which contained a large population of native Spanish speakers and immigrant students. To fully 
engage these students and stimulate learning, it was necessary to make the curriculum and environment culturally and linguistically responsive.

Susan's quote indicates that she had become aware of several factors that influence the education of MLLs. The starting point was the need to learn about the students' backgrounds, which was motivated by a desire to make content relevant to their lives. Susan also demonstrated her understanding of the connections between relevant content and positive learning outcomes for MLLs.

In addition in the final TMs, the phrase "funds of knowledge" was used by 50\% (six out of the 12 participants who wrote TMs) of the students, which may be related to "linguistic responsiveness" in the students' education philosophies. However, the TCs often used this phrase without giving a clear definition or context, so it was difficult to extract whether the TCs were using it to indicate a sociolinguistic consciousness, a value for diversity, the importance of knowing their MLL students, an understanding of a key principle of SLA, or a strategy for scaffolding, or even more than one LRT subdomain.

Finally, Erin, a TC who demonstrated relatively high LRT perceptions by the final draft of the TM, was a participant who did not mention "language" or any associated term, including "culture/ cultural," in her first draft. However, in the second draft, she had begun to incorporate aspects of sociolinguistic consciousness and identifying the language demands of classroom tasks:

[As a teacher, I believe] that existing structures of power and privilege need to change in order for a greater number of students to achieve success both inside and outside of the classroom. ... . [and] that I will enter the classroom with biases, both conscious and unconscious. [As a teacher, I will] constantly evaluate my actions in light of my biases/assumptions in order to ensure fairness for all my students . . . [and] create actionable content and language objectives.

In the second draft, Erin also mentioned the importance of "a needs-responsive classroom" and "a caring learning community wherein every student feels respected and valued," which suggested a commitment to know her MLLs and a value for linguistic diversity. 
Furthermore, by the final draft, Erin had added specific linguistic scaffolding strategies she used in an internship, such as graphic organizers, think-pair-share, packets on reading strategies, and choice in assignment.

Overall, analysis shows that one-third of the TCs never mentioned language in reference to their teaching philosophy in their TMs. Furthermore, none of the TCs introduced the topic of language in education for the first time in their final TM; if they were to mention language, they always did it before their final version. None of the TCs demonstrated in any TM version an inclination to advocate for MLLs. Also, the timing of the first mention, whether it came in the first, second, or third draft, did not seem to impact how extensively their perceptions of LRT were expressed by the final draft. Finally, the fact that some TCs made revisions to their ideas about language and education also did not clearly influence how extensively their presentation of LRT perspectives were expressed in the final draft.

\section{Implications and conclusion}

Anxiety and fear of teaching and learning with MLLs were noted across all data sources and is summed up by a participant: "My fear was that I would not be able to relate to or help those children because I was of a different demographic." Thirty-one percent of all participants associated emotions such as stress, anxiety, fear, culture shock, and being overwhelmed with MLLs. These fears expressed by the participants $(n=11)$ are worrisome and problematic for the field of teacher education as it positions MLLs as a threat and obstacle to be avoided and/or ignored. One participant stated, "I was really anxious about second language learners and not being able to communicate." Furthermore, scaffolding instruction for MLLs was viewed as "lots of extra work" that could potentially ruin a novice teacher's experience and performance evaluations. It is important for teacher educators to acknowledge and proactively work to overcome the fears of new teachers by taking concrete steps to address such fears through teacher education curriculum, internships, mentoring, and skill building.

While overall our study participants did not share extensive perspectives related to the LRT framework, the most frequently discussed aspect (though still low, with only 33\% of the participants discussing 
it) was related to teaching strategies and scaffolding. As new professionals in a demanding field, this is somewhat understandable but also suggests some thought and attention from teacher educators, particularly in conjunction with the anxieties and fears discussed previously, is necessary. The LRT framework specifically highlights both orientations and skills/knowledge. Due to the anxieties our participants expressed, this combination may be vital to the development of TC and novice teacher LRT skills. Without attention to both, TCs and novice teachers could fall victim to the overtechnicist and dehumanizing perspectives critiqued by Bartolomé (1994) as a "methods fetish.” We urge teacher educators to support teachers in overcoming their anxieties about working with MLLs and develop expansive LRT orientations and skills/knowledge to ensure that this does not occur.

Additionally, while we find the LRT framework to be extremely useful in guiding teacher education practices, we did note the absence of attention to assessment, something that is very important in the lives of new teachers and was frequently discussed by our participants. Further, in this time of shifting perspectives on bilingualism and bilingual development, future work with the framework should take the latest perspectives into account about languaging and translanguaging (García \& Wei, 2014). The skills and knowledge aspects of understanding second language acquisition could be expanded to include a usage-based linguistics perspective (Ortega, 2014) that emphasizes the "multilingual turn" (May, 2013) in second language acquisition and language as a social process (Váldes, Poza, \& Brooks, 2015). While the data collected and examined for this study focused on LRT as Lucas and Villegas published it in 2011, we think these perspectives are important to take into account for future work with the LRT framework as research on LRT and the preparation of teachers of MLLs grows.

The participants in this study $(N=36)$ showed a varying range of perceptions about linguistically responsive teaching, with the highest occurrence for scaffolding instruction and lowest for understanding key principles of second language learning as shown in Table 2. While we would still want more of our participants to discuss scaffolding as well as to do it in more complex, nuanced, and Vygotskyinformed ways (e.g., Tharp, Estrada, Dalton, \& Yamauchi, 200o), it is not surprising that they discussed teaching MLLs mostly in terms of various strategies and supportive approaches to their learning as 
initial teachers in the field still developing their craft. Furthermore, in the longitudinal part of our study, all TCs demonstrated changes in their education philosophy through the TM iterations, as is to be expected when teachers participate in a teacher education program. However, examining 12 TCs' 48 TMs specifically with reference to the LRT framework, while illuminating, did not provide enough evidence to identify reliable patterns of LRT development. Overall, our research suggests that while TCs and novice teachers did discuss various aspects of the LRT framework in their reflections on their learning, much more work is necessary to prepare linguistically responsive teachers. Some of the reasons for the low impact of the LRT framework could be attributed to the fear of working with MLLs as well as the lack of experience in teaching in urban classrooms.

Overall the aspects of the LRT framework that our analysis uncovered in the TCs/novice teachers' discussions of learning to teach suggest two important issues for further research: (a) What can we reasonably expect from TCs/novice teachers as they are learning to teach as well as developing LRT orientations and knowledge/skills?, and (b) What would a reasonable learning trajectory look like to help TCs/novice teachers develop strong LRT orientations and knowledge/ skills over time across the lifetime of their careers? The results of our study provide a useful foundation for expansive, necessary research on both of these questions.

\section{References}

Baecher, L. (2012). Feedback from the field: What novice preK-12 ESL teachers want to tell TESOL teacher educators. TESOL Quarterly, 46(3), 578-588. doi:10.1002/tesq.43

Bartolome, L. (1994). Beyond the methods fetish: Toward a humanizing pedagogy. Harvard Educational Review, 64(2), 173-195. doi:10.17763/ haer.64.2.58q5m5744t325730

Brisk, M. E. (2008). Language, culture, and community in teacher education. Mahwah, NJ: Lawrence Erlbaum.

Bunch, G. C. (2013). Pedagogical language knowledge preparing mainstream teachers for English learners in the new standards era. Review of Research in Education, 37(1), 298-341. doi:10.3102/oo91732X12461772

Daniel, S. (2014). Learning to educate English language learners in pre-service elementary practicums. Teacher Education Quarterly, 41(2), 5-28. 
De Jong, E. J., \& Harper, C. A. (2005). Preparing mainstream teachers for English language learners: Is being a good teacher good enough? Teacher Education Quarterly, 32(2), 101-124.

De Jong, E. J., \& Harper, C. A. (2008). ESL is good teaching "plus": Preparing standard curriculum teachers for all learners. In M. E. Brisk (Ed.), Language, culture, and community in teacher education (pp. 127-148). New York, NY: Lawrence Erlbaum.

Faltis, C. J., \& Valdés, G. (2016). Preparing teachers for teaching in and advocating for linguistically diverse classrooms: A vade mecum for teacher educators. In Gitomer \& C. A. Bell (Eds.), Handbook of research on teaching (pp. 549-592). Washington, DC: American Educational Research Association.

Freeman, Y. S., \& Freeman, D. E. (Eds). (2014). Research on preparing preservice teachers to work effectively with emergent bilinguals. Bingley, UK: Emerald Group.

García, O., \& Wei, L. (2014). Translanguaging: Language, bilingualism and education. New York, NY: Palgrave Macmillan.

Glenn, W. J., \& Gort, M. (2014). Preservice teachers' evolving knowledge and practice toward linguistically and culturally responsive pedagogy. In T. H. Levine, E. R. Howard, \& D. M. Moss (Eds.), Preparing classroom teachers to succeed with second language learners: Lessons from a faculty learning community (pp. 190-215). New York, NY: Routledge.

Goldenberg, C., \& Coleman, R. (2010). Promoting academic achievement among English learners: A guide to the research. Thousand Oaks, CA: Corwin.

Heidegger, M. (1982). The basic problems of phenomenology (A. Hofstadter, Trans.).Bloomington, IN: Indiana University Press.(Original German work published 1975; text of a lecture course in 1927)

Husserl, E. (1963). Ideas: A general introduction to pure phenomenology (W. R. Boyce Gibson, Trans.). New York, NY: Collier Books.

Jiménez-Silva, M., Olson, K., \& Jiménez Hernández, N. J. (2012). The confidence to teach English language learners: Exploring coursework's role in developing preservice teachers' efficacy. The Teacher Educator, 47(1), 9-28. doi:10.1080/o 8878730.2011.632471

Katz, S. R. (2000). Promoting bilingualism in the era of Unz: Making sense of the gap between research, policy, and practice in teacher education. Multicultural Education, 8(1), 2-7.

Levine, T. H., Howard, E. R., \& Moss, D. M. (Eds.). (2014). Preparing classroom teachers to succeed with second language learners: Lessons from a faculty learning community. New York, NY: Routledge.

Li, Xi. \& Zhang, M. (2004). "Why Mei still cannot read and what can be done." Journal of Adolescent \& Adult Literacy. 48(2), 92-101.

Lin, C. S. (2013). Revealing the "essence" of things: Using phenomenology in LIS research. Qualitative and Quantitative Methods in Libraries, 4, 469-478.

López, F., Scanlan, M., \& Gundrum, B. (2013). Preparing teachers of English language learners: Empirical evidence and policy implications. Education Policy Analysis Archives, 21, 20. doi:10.14507/epaa.v21n20.2013 
Lucas, T. (Ed.). (2011). Teacher preparation for linguistically diverse classrooms: A resource for teacher educators. New York, NY: Routledge.

Lucas, T., \& Grinberg, J. (2008). Responding to the linguistic reality of mainstream classrooms: Preparing all teachers to teach English language learners. In M. Cochran-Smith, S. Feiman-Nemser, D. J. McIntyre, \& K. E. Demers (Eds.), Handbook of research on teacher education: Enduring questions in changing contexts (pp. 606-636). New York, NY: Routledge/Taylor \& Francis Group and The Association of Teacher Educators.

Lucas, T., \& Villegas, A. M. (2010). The missing piece in teacher education: The preparation of linguistically responsive teachers. The Yearbook of the National Society for the Study of Education, 109(2), 297-318.

Lucas, T., \& Villegas, A. M. (2011). A framework for preparing linguistically responsive teachers. In T. Lucas (Ed.), Teacher preparation for linguistically diverse classrooms: A resource for teacher educators (pp. 55-72). New York, NY: Routledge.

Lucas, T., Villegas, A. M., \& Freedson-González, M. (2008). Linguistically responsive teacher education: Preparing classroom teachers to teach English language learners. Journal of Teacher Education, 29(4), 361-373. doi:10.1177/0022487108322110

May, S. (Ed.). (2013). The multilingual turn: Implications for SLA, TESOL, and bilingual education. New York, NY: Routledge.

Meskill, C. (2005). Infusing English language learner issues throughout professional educator curricula: The training all teachers project. Teachers College Record, 107(4), 739-756.

Minaya-Rowe, L. (2004). Training teachers of English language learners using their students' first language. Journal of Latinos \& Education, 3(1), 3-24. doi:10.1207/s1532771xjleo301_2

Niño, M. C. (2012). Challenging preservice teacher perspectives: Immigration, equitable opportunity, and advocacy. Teacher Education and Practice, 25(4), 521-535.

O'Hara, S., \& Pritchard, R. H. (2008). Meeting the challenge of diversity: Professional development for teacher educators. Teacher Education Quarterly, 35(1), 43-61.

Ortega, L. (2014). Ways forward for a bi/multilingual turn in SLA. In S. May (Ed), The multilingual turn: Implications for SLA, TESOL and bilingual education. New York, NY: Routledge.

Pappamihiel, N. E. (2001). Moving from the ESL classroom into the mainstream: An investigation of English language anxiety in Mexican girls. Bilingual Research Journal, 25(1-2), 31-38.

Pappamihiel, N. E. (2002). English as a second language students and English language anxiety: Issues in the mainstream classroom. Research in the Teaching of English, 327-355.

Pappamihiel, E. (2007). Helping preservice content-area teachers relate to English language learners: An investigation of attitudes and beliefs. TESL Canada Journal, 24(2), 42-6o. doi:10.18806/tesl.v24i2.138 
Reeves, J. (2009). Teacher investment in learner identity. Teaching \& Teacher Education, 25, 34-41. doi:10.1016/j.tate.2008.06.003

Rueda, R., \& Stillman, J. (2012). The 21st century teacher: A cultural perspective. Journal of Teacher Education, 63(4), 245-253. doi:10.1177/0022487112446511

Schall-Leckrone, L., \& McQuillan, P. (2014). Collaboration within a teacher education program: Preparing history teachers to teach English learners. In J. F. Nagle (Ed.), English learner instruction through collaboration and inquiry in teacher education (pp. 83-100). Charlotte, NC: Information Age.

Schwarzer, D., \& Fuchs, M. (2014). Monolingual teacher candidates promoting translingualism: A self-study of teacher education practices project. In Y. Freeman \& D. Freeman (Eds.), Research on preparing preservice teachers to work effectively with emergent bilinguals (pp. 89-112). Bingley, UK: Emerald Group.

Singh, S., \& Suárez-Orozco, M. M. (2012). The "generous heart": Teachers and immigrants in the 21st century. Teacher Education and Practice, 25(4), 585-588.

Sowa, P. A. (2009). Understanding our learners and developing reflective practice: Conducting action research with English language learners. Teaching and Teacher Education: An International Journal of Research and Studies, 25(8), 1026-1032. doi:10.1016/j.tate.2009.04.008

Strauss, A., \& Corbin, J. (1998). Basics of qualitative research: Techniques and procedures for developing grounded theory. Thousand Oaks, CA: Sage.

Tharp, R. G., Estrada, P., Dalton, S. S., \& Yamauchi, L. A. (2000). Teaching transformed: Achieving excellence, fairness, inclusion, and harmony. Boulder, CO: Westview Press.

Torok, C. E., \& Aguilar, T. E. (2000). Changes in preservice teachers' knowledge and beliefs about language issues. Equity \& Excellence in Education, 33(2), 2431. doi:10.1080/1066568000330205

Turkan, S., De Oliveira, L. S., Lee, O., \& Phelps, G. (2014). Proposing a knowledge base for teaching academic content to English language learners: Disciplinary linguistic knowledge. Teachers College Record, 116 (3), 1-30.

Valdés, G. (1998). The world outside and inside schools: Language and immigrant children. Educational Researcher, 27 (6), 4-18.

Valdés, G., Poza, L., \& Brooks, M. D. (2015). Language acquisition in bilingual education. In W. Wright, S. Boun, \& O. García (Eds.), The handbook of bilingual and multilingual education (pp. 56-74). Malden, MA: Wiley-Blackwell. Van Manen, M. (1990). Researching lived experience: Human science for an action sensitive pedagogy. Albany, NY: SUNY Press.

Virtue, D. C. (2009). Using "ESOL rounds" to prepare middle level candidates for work with English language learners. Middle Grades Research Journal, 4(1), $1-24$.

Vygotsky, L. (1978). Interaction between learning and development. Readings on the Development of Children, 23(3), 34-41. 
Wade, S. E., Fauske, J. R., \& Thompson, A. (2008). Prospective teachers' problem solving in online peer-led dialogues. American Educational Research Journal, 45(2), 398-442. doi:10.3102/0002831207308224

Walker, A., Shafer, J., \& Liams, M. (2004) 'Not in my classroom': Teacher attitudes towards English language learners in the mainstream classroom. NABE Journal of Research \& Practice, 2(1), 130-16o.

Warren, S. R., Reeder, G. M., Noftle, J. T., Kaiser, G. J., \& Jurchan-Rizzo, J. (2010). Preparing teachers to support English language learners. TESOL Journal, 1(3), 291-314. doi:10.5054/tj.2010.226826

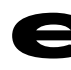

\section{Authors}

Madhavi Tandon, PhD, is Head of Symbiosis Schools Central Directorate, Pune, India. Her research focuses on equitable policy for multilingual learners marginalized at the intersection of language, race, and socioeconomic status within the classroom.

Kara Mitchell Viesca, PhD, was formally an Assistant Professor of Culturally and Linguistically Diverse Education at the University of Colorado Denver. Her research centers on advancing equity in the policy and practice of educator development, particularly for general education teachers of multilingual learners. She is now Associate Professor in the Department of Teaching, Learning \& Teacher Education at the University of Nebraska-Lincoln.

Colin Hueston is a third-year doctoral student in Education and Human Development at the University of Colorado Denver. His primary areas of focus are language education and sociocultural theory. During the summer, he serves as a visiting faculty member at the International University of Japan, where he works with students from developing countries who receive scholarships from the International Monetary Fund.

Tamara Milbourn is a PhD candidate in Educational Foundations, Policy and Practice at the University of Colorado Boulder. Her research investigates issues in American education related to mono/multilingualism, with an emphasis on issues of equity as connected to language practices and academic norms.

Supplemental material follows. 


\section{Appendix A}

Alumni Interview Protocol

Protocol: 12-0974

Title: Research on Graduates

\section{Introduction:}

\section{Open Ended Interview Protocol \# 1 - November}

Now that you've been in the classroom for a few months we're going to ask you some questions that brings us up to date on your school setting and students, how you've settled into teaching, and then ask just a bit about the future.

We'll start with some general questions about your school and schedule.

Let's start with a look at the school itself, your students, and the people you work with:

1. Tell me about your school...how would you describe it?

Probes:

- What kind of resources do they have? Or lack?

- What are the population demographics?

- Are parents involved in the school?

- What kind of goals does the school promote? Is there a mission statement? If so, do both faculty and students buy into it?

- Is there anything major that has happened at the school (AYP problems, new principal, new curriculum they have to use, construction)

- Is this a very different setting from your internship experience(s)?

2. Let's shift to your students for a bit. I'd like you to describe them to me. Can you start with some general demographics that describe the pupils in your class(es)?

Probes:

- Age, ethnicity, race, language backgrounds, SES

- SPED

- Multilingual learners

- Range of abilities across the group(s)

- Did you get some of this information from teachers who had these students previously? Did you have prior experience with any of these pupils?

- How would you describe classroom dynamics? Do you have difficulty with certain students or a particular class?

- What is the biggest challenge you have faced so far this year?

3. At this point in the school year, are you able to identify goals for your students? Probes:

- What do you want them to learn? (consider academic, social, and emotional possibilities, here) 
4. Learning to teach for social justice and equity is a major focus of UCTE. We are interested in the realities of how this plays out in practice.

Probes:

- Do you think about issues of social justice in your classroom?

- In your planning?

- Do feel that teaching for social justice is an explicit part of your classroom experience at the moment?

- How might this be particular to the context of your school? Classroom?

- How practical is the UCTE emphasis on social justice for a novice teacher?

- Has your view on teaching for social justice changed over the first few months of fulltime teaching? If so, how and why?

5. How do you know your pupils are learning? Be specific about the way you get this kind of information ...

Probe:

- Has this changed in anyway since your internships? If so, why?

- Has your TWS played a role in how you look at your classes?

6. What kind of relationships have you been able to develop with school faculty, staff, students, parents and community members?

Probes:

- Principal, department head, fellow teachers

- Is there a lot of interaction among faculty?

- Do you have the opportunity to co-plan or co-teach?

- What kind of relationships do you have with students? What kinds of roles are students playing in your classroom and teaching?

- What about with parents and community members? What role do they play at your school? In your classroom?

7. Have you been an assigned a mentor or participate in an induction program? If so, has this been a successful match?

Probes:

- Are there other people that might be seen as informal mentors or part of your network of support - including friends and family outside of school?

Let's spend a few minutes talking about your immersion into fulltime teaching.

8. In general, how do you feel things have gone in the past few months?

9. What is your workload like?

Probes:

- What is your schedule? When do you get in to school? What time do you leave?

- For secondary - number of preps?

- For elementary - breaks?

- Additional school duties (ex: study hall, cafeteria duty, extra-curriculuar activities?) 
10. Tell me about planning...when do you get to do this? How do you decide what to use? What to teach?

Probes:

- What resources do you have? Use? Where are they from?

- Are you focusing on day-to-day planning or do you have a long-term plan to work from?

- What strategies/resources have you utilized from UCTE?

11. How did you plan for this topic that you assessed here (look at the pupil work that the teacher brings to the interview)?

- Why did you choose to assess your students using this assignment?

- How would you change it if you were to do it again?

12. Do you see yourself as having a great deal of autonomy in your classroom?

(If teacher asks what you mean by 'autonomy' can say 'when some people talk about autonomy they refer to the role of standards, district mandated curriculum or exams, whether you feel you have a voice in deciding what is taught in your classroom)

Probes:

Why/why not?

In what area do you have most/least autonomy?

Who or what influences your decisions in the classroom?

Is CSAP/TCAP a driving force in what you do?

Let's look at how well prepared you feel and what you attribute to the UCTE experience:

13. What did you feel prepared for? Not prepared for?

Probes:

- Is there anything that you feel UCTE did not prepare you for?

- Is there any one thing that you feel especially well prepared for by the UCTE program?

- Does your school provide support through PD for what you might not feel prepared for?

- Where might you turn for additional support/knowledge?

- Do you feel prepared to work with the population of students in your classroom?

(Multilingual, SPED, Gifted and Talented, etc.)

14. Is teaching what you expected it to be? Have your aspirations for a career in teaching changed?

- Do you think you'll teach next year?

- In this school? For how long?

15. Is there anything that we haven't touched on that you feel is especially important to include in this conversation? 


\section{Focus Group Protocols}

Protocol: 12-0973

Title: Research on Pre-Service Work

\section{Focus Group Guides (Teacher Candidates)}

Focus Group \#1 (at the beginning of Internship 1, after completing first two courses in the program)

This focus group will center around why students chose UCTE and what their initial experiences and perspectives are.

Sample questions:

- Let's talk about why you all ended up in UCTE. How did you choose to come here? What do you hope to learn about teaching while you are here? What are your expectations for your experience in UCTE? What do you think the program will offer?

- Let's talk about why you are all becoming teachers. Why are you interested in teaching? How did you experience school (K-12) as a student? (both as a learner and socially) Do you think you received a good education?

- UCTE has an explicit social justice and equity mission. What does it mean to you to teach for social justice? How do you think teaching for social justice plays out in classrooms? What have you learned about teaching for social justice since you've been in UCTE? Are there more things you would like to learn?

- Let's talk about your internship. What are you looking forward to in your internship? Is there anything you are concerned about? What challenges do you think you will face? What skills do you think you will need to be able to successfully manage those challenges?

- Let's talk about your impressions of UCTE so far. What have been the strengths in your experiences? What have been the weaknesses? Any suggestions for improvement?

Optional:

- Let's talk about the ideal school to work in, what would it be like? Now let's talk about where you see yourself working next year after you graduate. What kind of job do you see yourself getting?

- Let's talk about what the ideal classroom looks like. How will you teach? What will your relationships with students, parents, colleagues, administration, etc. look like? What will the classroom climate be like?

Focus Group \#2 (at the beginning of Internship 2, after completing half of the program) This focus group will center around experiences in their internship and learning so far in the program.

We'll send the sample questions in advance along with a brief description of what a focus group is, what it looks like and how we hope the conversation will go.

Sample questions: 
1. Let's talk about your internship. What do you think of the structure of the internships? What is your co-teaching role in the classroom? What is the school environment and community like? What is the role of your clinical teacher in shaping your practice and philosophy? What about your site professor and coordinator? What about your collaborative learning community (CLC)? Have you seen any moments of teaching that were particularly noteworthy? What made them such?

2. Let's talk about your students. What have you learned from working with them? Are there things that you feel like you should learn in UCTE courses to help you better work with your students? Are there students you are particularly impressed with? Concerned about? Why?

3. Let's talk about your developing practice. What do you see as your strengths and weaknesses as a teacher so far? What are you learning about how children learn? Based on your experiences so far, what would you say are the most important skills and knowledge for teaching? Based on your experiences so far, have you changed your plans on where and how you'd like to teach?

4. Let's talk about teaching for social justice and equity. Have you seen examples of teaching for social justice and equity in your internships? What did they look like? Is there anything you would have done differently? How do you feel about other schools not adhering to some of the UCTE philosophies? Do you have ideas, philosophies or commitments that you are struggling to figure out how to put into practice? Explain. What does being an urban educator mean to you, your identity, and your heart?

5. Let's talk about your impressions of UCTE so far. What have been the strengths in your experiences? What have been the weaknesses? Any suggestions for improvement? What does being an urban educator mean to you, your identity, and your heart?

Focus Group \#3 (at the beginning of Internship 3, the last semester in the program) This focus group will center around reflecting on learning in each course as well as the $2^{\text {nd }}$ internship.

Sample Questions:

- Let's talk about your learning opportunities in UCTE so far. What course or courses have really stood out for you? Why? Do you think these courses have helped you understand the realities of schools today as well as what is possible for school improvement? How is your coursework connecting/disconnecting with your experiences in the internship?

- Let's talk about your learning opportunities around various topics. What have you learned about working with multilingual learners? Students with special needs? Gifted and talented students? Effective assessment? Student learning? Data informed decision making? Effective pedagogy (including CREDE) specific to content areas? Other topics you feel have been key to your development as an educator?

- Let's talk about your experiences in your internships. What things have you learned from your clinical teacher? What things have you learned from your site teams? What aspect of the internship has been most effective to support your learning? What aspect of the internship has been least effective to support your learning?

- Let's talk about teaching for social justice. What is teaching for social justice and equity? Can you identify specific examples of learning experiences in the program where you 
have seen social justice and equity modeled for you? What does being an urban educator mean to you, your identity, and your heart?

- Let's talk about final learning goals. As you go into your last semester of UCTE, what are some things you are focusing on as you continue to develop your practice? What do you hope to accomplish in your third internship? How will you know if you have met your goals?

- Let's talk about your impressions of UCTE so far. What have been the strengths in your experiences? What have been the weaknesses? Any suggestions for improvement?

Focus Group \#4 (after all program requirements have been completed)

This focus group will center around overarching learning in UCTE and summary of experiences.

\section{Sample Questions:}

- You've been in schools for a year and have finished all the requirements of UCTE. What would you say you have learned about yourself as a teacher? As a learner? What did you learn about teaching/the activity of teaching? What's the hardest thing? What's the easiest? What most surprised you? What has had the greatest impact on your learning during your time in UCTE?

- Let's focus on your learning. What's the most important thing you've learned about teaching specific content (like math, science, etc.)? (Where did you learn it from?) What have you learned about teaching literacy? (Where did you learn it from?) What have you learned about diverse learners? (Where did you learn it from?) (probe: for multilingual students, students with special needs, gifted and talented, etc.) What aspect about teaching do you feel the most/least prepared?

- As you complete your teacher education experience, what do you make of the idea of teaching for social justice and equity? Has your definition changed? What has impacted your perspective on teaching for social justice and equity? Can you identify specific examples of learning experiences in the program where you have seen social justice and equity modeled for you? How do you see yourself teaching for social justice in your own classroom?

- Let's talk about where you see yourself overtime. What are your professional goals as a teacher? How will you know if you have accomplished them? Where do you see yourself 3 years from now? 5 years? 10 years? Beyond that?

- Let's talk about UCTE as a whole program. If you could change something about the program, what would it be? Was there anything that was irrelevant in the program? What is something that you found especially valuable in the program? Any other suggestions or feedback for improvement? 